\title{
Reactive ion beam etching of aluminum indium antimonide, gallium indium antimonide heterostructures in electron cyclotron resonance methane/hydrogen/nitrogen/silicon tetrachloride discharges at room temperature
}

\author{
J. R. Sendra, ${ }^{\text {a) }}$ J. Anguita, J. J. Pérez-Camacho, and F. Briones \\ Instituto de Microelectónica de Madrid, CNM, CSIC, Serrano 144, 28006 Madrid, Spain
}

(Received 28 June 1995; accepted for publication 18 September 1995)

\begin{abstract}
Reactive ion beam etching of aluminum indium antimonide, gallium indium antimonide heterostructures in electron cyclotron resonance plasma using methane/hydrogen/nitrogen/silicon tetrachloride $\left(\mathrm{CH}_{4} / \mathrm{H}_{2} / \mathrm{N}_{2} / \mathrm{SiCl}_{4}\right)$ mixtures has been performed at room temperature. Due to the ratio of chlorine to methane, formation of an indium chloride layer on the etched surface is avoided, thus resulting, in etched surfaces as smooth as the original ones and flat mesa sidewalls. Infrared diodes $(2.3 \mu \mathrm{m})$ have been fabricated using this etching technology. () 1995 American Institute of Physics.
\end{abstract}

$\mathrm{Ga}_{1-x} \mathrm{In}_{x} \mathrm{Sb}-\mathrm{Al}_{y} \mathrm{Sb}$ heterostructures are very promising due to their potential use in multiple quantum well (MQW) photodetectors in the $2-5 \mu \mathrm{m}$ range, with wide applications in the gas sensing field. $\mathrm{Ga}_{1-x} \mathrm{In}_{x} \mathrm{Sb}$ is the base material of the well because of its band gap in the midinfrared region of the spectrum, while $\mathrm{Al}_{1-y} \mathrm{In}_{y S b}$ provides the necessary barrier for quantum confinement. The In content must be slightly different in the well and in the barrier in order to match the lattice parameters of both compounds. A suitable composition of these ternaries is $x=0.40$ and $y=0.35^{1,2}$ as we focused on the detection in the vibrational band of methane at $2.3 \mu \mathrm{m}$. To obtain actual photodiode devices, it is necessary to develop dry etching techniques that allow controlled and nonselective etching of the In-containing layers with smooth etched surfaces and flat mesa sidewalls for further processing.

It is well known that chlorine based plasmas have some limitations when etching indium-containing compounds at room temperature. Formation of a low volatility residual layer of $\mathrm{InCl}_{x}$ seems to be the cause of the rough morphologies of the etched surfaces. ${ }^{3,4}$ Etching at high temperature $\left(>200{ }^{\circ} \mathrm{C}\right)$ is then crucial in order to increase the thermal desorption of that layer and hence achieve a successful etching process. ${ }^{5,6}$ However, many commercial etching systems are not designed to provide this high temperature operation and its implementation is rather difficult in a production environment. Methane-based plasmas can overcome those limitations, as has been widely reported. ${ }^{7,8}$ In particular, reactive ion beam etching (RIBE) of InP using electron cyclotron resonance (ECR) discharges in $\mathrm{CH}_{4} / \mathrm{H}_{2} / \mathrm{N}_{2}$ chemistry has revealed very good etching characteristics, leaving mirrorlike etched surfaces with no polymer deposition and little and shallow electrical damage. ${ }^{9}$ With regard to $\mathrm{Ga}, \mathrm{Al}$, and $\mathrm{Sb}$ elements, either $\mathrm{GaSb}$ and AlSb can be etched in chlorinated plasmas with good performances at the right etching conditions. ${ }^{10}$ However, these compounds (and especially those containing $\mathrm{Al}$ ) are not efficiently etched in $\mathrm{CH}_{4}$-based plasmas ${ }^{11}$ unless high acceleration voltages are used, leading

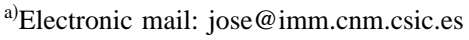

to unacceptable rough surfaces. ${ }^{12}$ For all these reasons, we have assumed that ECR discharges of methane/chlorine mixtures could take advantage of both plasma chemistries in etching $\mathrm{Al}_{1-y} \mathrm{In}_{y} \mathrm{Sb}$. In this letter, we report on the $\mathrm{CH}_{4} / \mathrm{H}_{2} / \mathrm{N}_{2} / \mathrm{SiCl}_{4}$ plasma mixture compositions and ion acceleration voltages suitable for the ECR-RIBE etching of $\mathrm{Ga}_{0.6} \mathrm{In}_{0.4} \mathrm{Sb} \mathrm{Al}_{0.65} \mathrm{In}_{0.35} \mathrm{Sb}$ heterostructures at room temperature and its application to the fabrication of photodiodes.

We used a commercial load-lock ECR-RIBE system in these experiments. Details about the system can be found elsewhere. ${ }^{9}$ The microwave power was set at $300 \mathrm{~W}$. Ion acceleration voltages $\left(V_{\text {acc }}\right)$ from 200 to $700 \mathrm{~V}$ were used. All the experiments were performed at room temperature. Ion beam current densities were measured by a Faraday cup placed above the sample holder. The samples were grown on Si-doped (100) GaAs substrates by molecular beam epitaxy (MBE) at temperatures ranging between 420 and $460{ }^{\circ} \mathrm{C}$. A $30 \AA$ thick GaInSb layer was grown over AlInSb layers in order to avoid $\mathrm{Al}$ oxidation. Further details about the growth procedure will be published elsewhere. ${ }^{13}$ For the etching experiments, a $\mathrm{SiO}_{2}$ layer deposited by plasma-enhanced chemical vapor deposition (PECVD) at $300{ }^{\circ} \mathrm{C}$ was used as the masking material. A flow of $7 \mathrm{sccm}$ of $\mathrm{CH}_{4} / \mathrm{H}_{2}(15 \%$ of $\mathrm{CH}_{4}$ in the mixture) and $3 \mathrm{sccm}$ of $\mathrm{N}_{2}$ is used in all the experiments. Then a variable flow of $\mathrm{SiCl}_{4}(0.5,1$, and 2 sccm) was added, giving a content of $\mathrm{SiCl}_{4}$ of $4.8 \%, 9.1 \%$, and $16.7 \%$ in the $\mathrm{CH}_{4} / \mathrm{H}_{2} / \mathrm{N}_{2} / \mathrm{SiCl}_{4}$ mixture. Some etching experiments were performed in pure $\mathrm{SiCl}_{4}(2 \mathrm{sccm})$.

Figures 1(a) and 1(b) present the etch rates for $\mathrm{Al}_{0.65} \mathrm{In}_{0.35} \mathrm{Sb}$ and $\mathrm{Ga}_{0.6} \mathrm{In}_{0.4} \mathrm{Sb}$, respectively, as a function of $V_{\text {acc }}$ for the four gas mixtures. The most important feature is the existence of a threshold voltage $\left(V_{\mathrm{th}}\right)$ for obtaining measurable etch rates. We observed $V_{\mathrm{th}} \approx 200 \mathrm{~V}$ on both compounds in chloride rich conditions [curve 1 in Figs. 1(a) and 1(b)]. This value is similar to one previously found by other authors $^{14}$ in etch experiments (ECR-RIBE) of InP in $\mathrm{Cl}_{2}$ plasmas also at room temperature, where an $\mathrm{InCl}_{x}$ layer is formed. Figure 2(a) shows the rough surface obtained after $\mathrm{Al}_{0.65} \mathrm{In}_{0.35} \mathrm{Sb}$ etching in these chloride rich conditions at $V_{\text {acc }}=500 \mathrm{~V}$. On the other hand, $V_{\text {th }}$ rises to $400 \mathrm{~V}$ when 


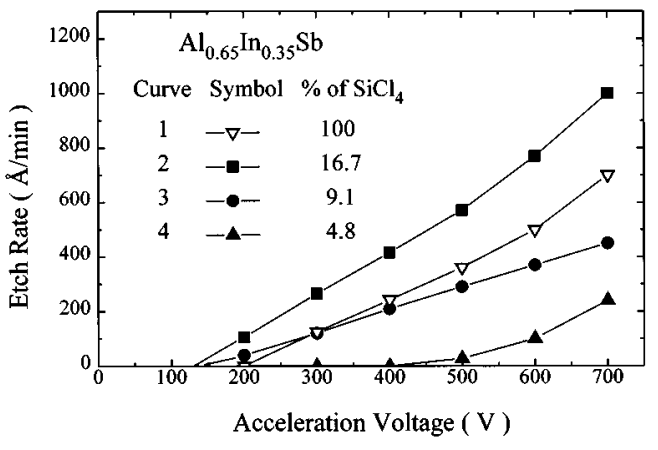

(a)

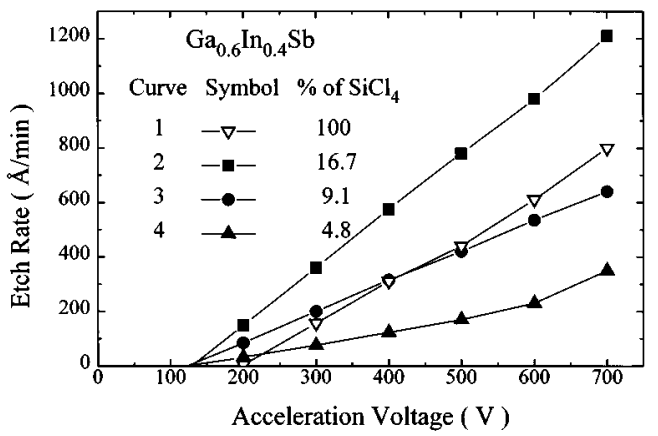

(b)

FIG. 1. Average etch rate of (a) $\mathrm{Al}_{0.65} \mathrm{In}_{0.35} \mathrm{Sb}$ and (b) $\mathrm{Ga}_{0.6} \mathrm{In}_{0.4} \mathrm{Sb}$ in ECR- $\mathrm{CH}_{4} / \mathrm{H}_{2} / \mathrm{N}_{2} \mathrm{SiCl}_{4}$ discharges as a function of acceleration voltage.

etching in very low partial pressure of chloride [curve 4 in Fig. 1(a)]. This high value agrees with the approximately 350 $\mathrm{V}$ found by other authors ${ }^{12}$ when etching AlInAs in ECR discharges of $\mathrm{CH}_{4} / \mathrm{H}_{2} / \mathrm{Ar}$. This high value of $V_{\text {th }}$ in low partial pressure of chloride requires a high $V_{\text {acc }}$, resulting in degraded morphologies. However, $V_{\mathrm{th}} \approx 130 \mathrm{~V}$ when etching $\mathrm{Ga}_{0.6} \mathrm{In}_{0.4} \mathrm{Sb}$ or $\mathrm{Al}_{0.65} \mathrm{In}_{0.35} \mathrm{Sb}$ in $\mathrm{CH}_{4} / \mathrm{H}_{2} / \mathrm{N}_{2} / \mathrm{SiCl}_{4}$ plasma at intermediate partial pressure of $\mathrm{SiCl}_{4}$ in the mixture [curves 2 and 3 in Figs. 1(a) and 1(b)]. This value is equal to the one found when etching InP in $\mathrm{CH}_{4} / \mathrm{H}_{2} / \mathrm{N}_{2}$ mixtures, ${ }^{9}$ suggesting that no $\mathrm{InCl}_{x}$ layer is formed at these $\mathrm{SiCl}_{4}$ partial pressures. Further evidence of the absence of an $\mathrm{InCl}_{x}$ layer is presented in Fig. 3, which shows the results of an energy dispersive spectroscopy (EDS) analysis on $\mathrm{Ga}_{0.6} \mathrm{In}_{0.4} \mathrm{Sb}$ surfaces after etching in pure $\mathrm{SiCl}_{4}$ and in $\mathrm{CH}_{4} / \mathrm{H}_{2} / \mathrm{N}_{2} / \mathrm{SiCl}_{4}$ discharges. Peaks corresponding to $\mathrm{Cl}$ and $\mathrm{Si}$ are measured with the

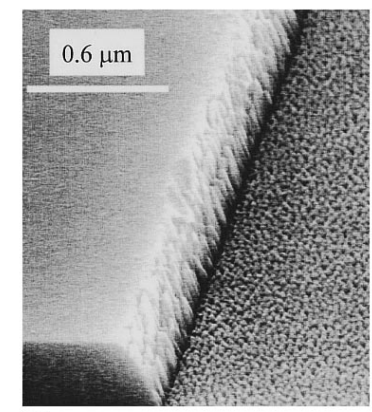

(a)

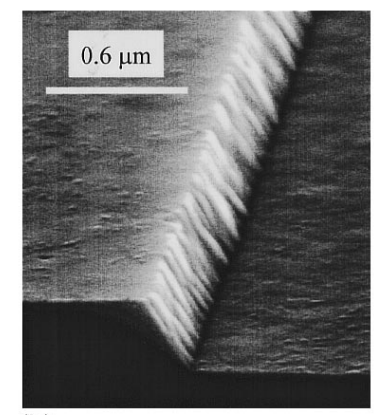

(b)
FIG. 2. SEM micrographs of $\mathrm{Al}_{0.65} \mathrm{In}_{0.35} \mathrm{Sb}$ etched at an ion acceleration voltage of $500 \mathrm{~V}$ : (a) ECR-SiCl 4 discharges; (b) $\mathrm{ECR}-\mathrm{CH}_{4} / \mathrm{H}_{2} / \mathrm{N}_{2} / \mathrm{SiCl}_{4}$ $(9.1 \%)$ discharges.

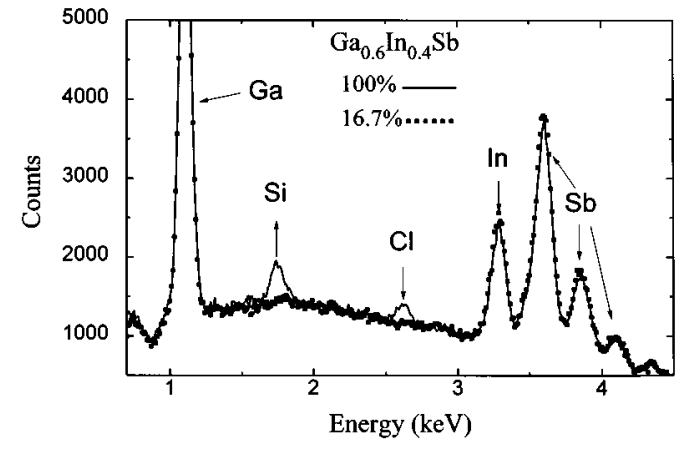

FIG. 3. EDS spectra of $\mathrm{Ga}_{0.6} \mathrm{In}_{0.4} \mathrm{Sb}$. Acceleration voltage $6 \mathrm{keV}$. Dead time $47 \%$. Accumulation time $100 \mathrm{~s}$.

former and no evidence of $\mathrm{InCl}_{x}$ is seen when using the mixture. In this case, smooth etched surfaces are obtained as shown in Fig. 2(b). This suggests that by using the appropriate partial pressure of chloride in $\mathrm{CH}_{4} / \mathrm{H}_{2} / \mathrm{N}_{2} / \mathrm{SiCl}_{4}$ mixtures, it is possible to etch In-containing compounds in an efficient way at room temperature and moderate ion acceleration voltages, without the formation of $\mathrm{InCl}_{x}$ layers confirming the previous assumptions about the possibilities of the $\mathrm{CH}_{4} / \mathrm{H}_{2} / \mathrm{N}_{2} / \mathrm{SiCl}_{4}$ chemistry. We speculate that in a certain range of partial pressures of $\mathrm{SiCl}_{4}$ in the mixture, indium is etched by methane-based reagents, while aluminum is totally removed by chloride-based ones. When $V_{\text {acc }}=500 \mathrm{~V}$ and $9.1 \%$ of $\mathrm{SiCl}_{4}$ in the mixture are used as the process parameters, $\mathrm{Ga}_{0.6} \mathrm{In}_{0.4} \mathrm{Sb}$ is etched at $400 \AA / \mathrm{min}$ while $\mathrm{Al}_{0.65} \mathrm{In}_{0.35} \mathrm{Sb}$ is etched at $300 \AA / \mathrm{min}$, resulting in an etch rate ratio of $\mathrm{Ga}_{0.6} \mathrm{In}_{0.4} \mathrm{Sb}$ to $\mathrm{Al}_{0.65} \mathrm{In}_{0.35} \mathrm{Sb}$ of only 1.3 , which provides a virtually nonselective mode of etching. Figure 4 shows the flat mesa sidewalls with smooth bottom surfaces obtained after the etching of complex AlInSb/GaInSb heterostructures in these conditions, which allow further processing (such as passivation and metal coatings).

A suitable way to determine the etch mechanism involved is the study of the ratio of the increase in etch rate to the increase in ion beam current density versus the ion acceleration voltage. Figure 5 shows this ratio as a function of $V_{\text {acc }}$ when etching $\mathrm{Al}_{0.65} \mathrm{In}_{0.35} \mathrm{Sb}$ in $\mathrm{CH}_{4} / \mathrm{H}_{2} / \mathrm{N}_{2} / \mathrm{SiCl}_{4}$ mixtures. It is observed that when etching with a very low partial pressure of chloride, the etch yield is strongly affected by ion bombardment, leading to a physical-like etching

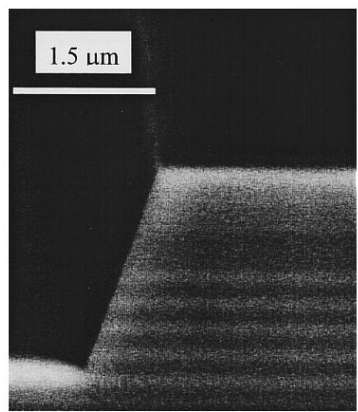

(a)

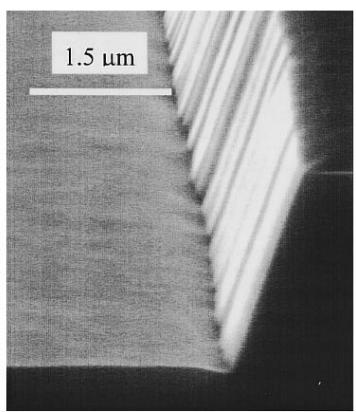

(b)
FIG. 4. Mesa sidewall of an AlInSb/GaInSb heterostructure etched at an ion accelerating voltage of $500 \mathrm{~V}$ with $\mathrm{ECR}-\mathrm{CH}_{4} / \mathrm{H}_{2} / \mathrm{N}_{2} / \mathrm{SiCl}_{4}(9.1 \%)$ discharges: (a) backscattering electrons image; (b) secondary electron image. 


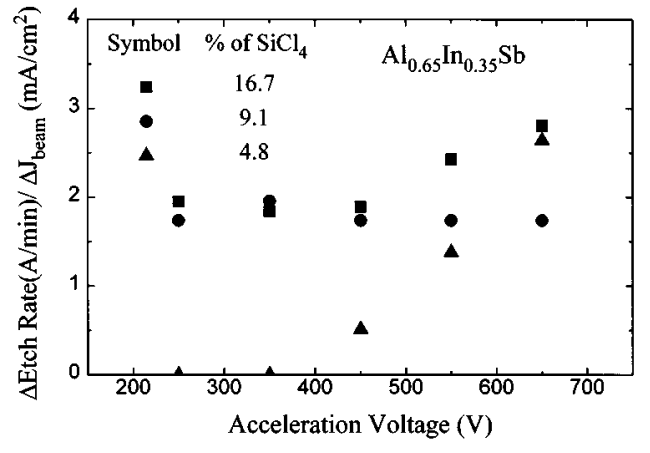

FIG. 5. Etch yield of $\mathrm{Al}_{0.65} \mathrm{In}_{0.35} \mathrm{Sb}$ in ECR- $\mathrm{CH}_{4} / \mathrm{H}_{2} / \mathrm{N}_{2} / \mathrm{SiCl}_{4}$ discharges as a function of ion acceleration voltage.

mechanism. ${ }^{15}$ The increase in the content of $\mathrm{SiCl}_{4}$ brings about a change to a chemical-like etching mechanism with little influence of the ion energy at high ion acceleration voltages. Etching in the chemical-like mode results in etched surfaces whose morphology equals the as-grown surfaces. Redeposition on the sidewalls of the sputtered etch products prevents undercutting and leads to the overcut mesa profile shown in Figs. 2(b) and 4.

MQW-pin photodiodes in an $n^{+}$GaAs substrate were fabricated using this etching technology. A $0.2 \mu \mathrm{m} n^{+}$-type GaAs buffer layer was first grown, followed by a $1 \mu \mathrm{m}$ $n^{+}$-type (SnTe) $\mathrm{Al}_{0.65} \mathrm{In}_{0.35} \mathrm{Sb}$ region. The $0.43 \mu \mathrm{m}$ intrinsic MQW region consisted of 33 undoped periods of $80 \AA$ $\mathrm{Ga}_{0.6} \mathrm{In}_{0.4} \mathrm{Sb}$ wells and $50 \AA \mathrm{Al}_{0.65} \mathrm{In}_{0.35} \mathrm{Sb}$ barriers. Then, the $0.3 p^{+}$-type $(\mathrm{Be}) \mathrm{Al}_{0.65} \mathrm{In}_{0.35} \mathrm{Sb}$ region was grown, followed by a $500 \AA p^{+}$-type $\mathrm{Ga}_{0.6} \mathrm{In}_{0.4} \mathrm{Sb}$ cap layer. Mesa structures with $100 \mu \mathrm{m}$ diameter and a height of $1.2 \mu \mathrm{m}$ were formed by dry etching for $40 \mathrm{~min}$ in $\mathrm{CH}_{4} / \mathrm{H}_{2} / \mathrm{N}_{2} / \mathrm{SiCl}_{4}$ discharges (9.1\% of $\mathrm{SiCl}_{4}$ in the mixture) at $V_{\text {acc }}=500 \mathrm{~V}$. A $0.4 \mu \mathrm{m} \mathrm{SiN}{ }_{x}$ PECVD layer deposited at $100{ }^{\circ} \mathrm{C}$ was used as passivation film. Contacts were then formed on the top $p^{+}$layer and on the $n^{+}-\mathrm{Al}_{0.65} \mathrm{In}_{0.35} \mathrm{Sb}$ region. The spectra response curve of a typical photodiode taken at $300 \mathrm{~K}$ in photovoltaic operation is shown in Fig. 6. The excitonic transition at $2.3 \mu \mathrm{m}$ and the transition associated with the different levels in the quantum well are clearly observed even at room temperature, thus confirming the quality of the etching process.

In conclusion, reactive ion beam etching of $\mathrm{AlInSb} /$ GaInSb heterostructures in an ECR plasma using $\mathrm{CH}_{4} / \mathrm{H}_{2} /$ $\mathrm{N}_{2} / \mathrm{SiCl}_{4}$ mixtures has been performed at room temperature.

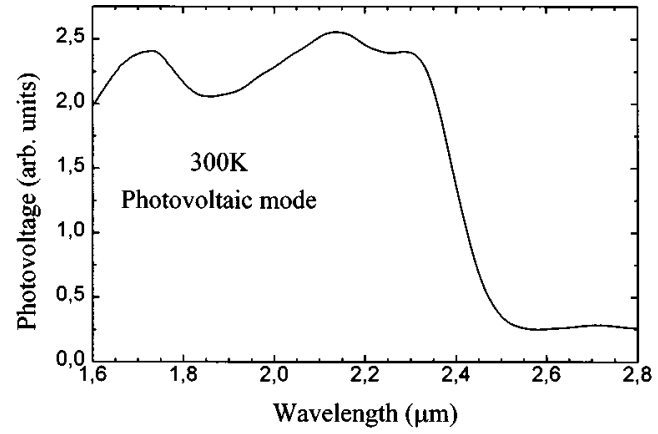

FIG. 6. Spectral response curve of a typical photodiode taken at $300 \mathrm{~K}$ in photovoltaic operation.

Due to the ratio of chloride to methane, formation of an $\mathrm{InCl}_{x}$ layer on the etched surface is avoided, thus resulting in etched surfaces as smooth as the original ones and flat mesa sidewalls. Infrared photodiodes $(2.3 \mu \mathrm{m})$ have been fabricated using this etching technology.

The authors wish to thank Dr. Carmen Quintana for the EDS measurements. The work was performed within ESPRIT Contract No. 6374 (MMMGas).

${ }^{1}$ G. Giesecke and H. Pfister, Acta Crystallogr. 11, 369 (1958).

${ }^{2}$ M. E. Straumanis and C. D. Kim, J. Appl. Phys. 36, 3822 (1965).

${ }^{3}$ D. G. Lisham and E. L. Hu, J. Vac. Sci. Technol. B 8, 1951 (1990).

${ }^{4}$ R. A. Baker, T. M. Mayer, and R. H. Burton, Appl. Phys. Lett. 40, 583 (1982).

${ }^{5}$ T. Yoshikawa, S. Kohmoto, M. Anan, N. Hamao, M. Baba, N. Takado, Y. Sugimoto, M. Sugimoto, and K. Asakawa, Jpn. J. Appl. Phys. 31, 4381 (1992).

${ }^{6}$ T. Yoshikawa, M. Moser, and K. Affolter, Proceedings of the 5th International Conference on InP and Related Materials, Paris, 1993, p. 533.

${ }^{7}$ J. Werking, J. Schamm, C. Nguyen, E. L. Hu, and H. Kroemer, Appl. Phys. Lett. 58, 2003 (1991).

${ }^{8}$ H. E. G. Arnot, R. W. Glew, G. Schiviani, L. J. Rigby, and A. Piccirillo, Appl. Phys. Lett. 62, 3189 (1993).

${ }^{9}$ J. R. Sendra and J. Anguita, Jpn. J. Appl. Phys. 33, L390 (1994).

${ }^{10}$ S. J. Pearton, U. K. Chakrabarti, W. S. Hobson, and A. P. Kinsella, J. Vac. Sci. Technol. B 8, 596 (1990).

${ }^{11}$ K. E. G. Arnot, R. W. Glew, G. Schiviani, L. J. Rigby, and A. Piccirillo, Appl. Phys. Lett. 62, 3189 (1993).

${ }^{12}$ S. C. Constantine, A. B. Emerson, W. S. Hobson, and A. P. Kinsella, J. Vac. Sci. Technol. B 8, 596 (1990).

${ }^{13}$ J. J. Pérez-Camacho, Ph.D. thesis, Universidad Politécnica de Madrid (1994).

${ }^{14}$ K. Mutoh, M. Nakajima, and M. Mihara, Jpn. J. Appl. Phys. 29, 1022 (1990).

${ }^{15}$ T. Tadokoro, F. Koyama, and K. Iga, Jpn. J. Appl. Phys. 27, 389 (1988). 